\title{
PEMBELAJARAN BAHASA SUNDA DI WILAYAH PERBATASAN: DILEMA IMPLEMENTASI KURIKULUM 2013
}

\author{
Lungguh Puri Pramswari
}

SDN Kayumanis 1 Kota Bogor

Jl. Pool Bina Marga Kota Bogor

Email: lakeisha.zihnie@gmail.com

\begin{abstract}
Curriculum 2013 provides flexibility to all practitioners of formal education to continue to develop local contentas a form of wealth typical of the region that needs to be maintained and preserved. One of the local content that its existence has importance values is Bahasa Sunda. Teaching Bahasa Sunda in a region where based on a strong Sundanese culture, will not encounter many obstacles. However, in the corners of the area which incidentally is the city/county with very heterogeneous demographi cconditions, of course teaching Bahasa Sunda will be filled with challenges. For example, in areas bordering other culture such Betawi and Java, because of the flexibility of the culture, Sundanese people will be influenced by the Betawior Javanese speech and cultured. This paper is the result of research conducted on the raised border of the city of Bogor, on the implementation of Curriculum 2013, which continued to develop local content Bahasa Sunda to equip students with the knowledge, skills, and attitude typical of Sundanese culture appropriate local wisdom. But on the other hand, collided with a dilemma, where border communitiesis very heterogeneous, so the Sundanese culture and language had not been well maintained.
\end{abstract} Keywords: local content, Sundanese, cultural borders.

ABSTRAK Kurikulum 2013 menyediakan fleksibilitas untuk semua praktisi pendidikan formal untuk terus mengembangkan konten lokal sebagai sebuah bentuk kekayaan khas daerah yang perlu dijaga dan dilestarikan. Salah satu muatan lokal yang keberadaannya memiliki nilai-nilai penting adalah Bahasa Sunda. Pengajaran Bahasa Sunda di daerah di mana didasarkan pada budaya Sunda yang kuat, tidak akan menghadapi banyak kendala. Namun, di sudut-sudut daerah yang notabene merupakan kota/kabupaten dengan kondisi demografis yang sangat heterogen, tentu saja mengajar Bahasa Sunda akan penuh dengan tantangan. Sebagai contoh, di daerah yang berbatasan dengan budaya lain seperti Betawi dan Jawa, karena fleksibilitas budaya, masyarakat Sunda akan dipengaruhi oleh bahasa dan budaya Betawi atau Jawa. Tulisan ini merupakan hasil penelitian yang dilakukan di perbatasan kota Bogor, pada pelaksanaan kurikulum 2013, yang terus mengembangkan konten Bahasa Sunda untuk membekali siswa dengan pengetahuan, keterampilan, dan sikap khas budaya Sunda yang sesuai dengan kearifan lokal. Namun di sisi lain, bertabrakan dengan dilema, di mana masyarakat perbatasan sangat heterogen, sehingga budaya dan bahasa Sunda tidak terpelihara dengan baik.

Kata kunci: konten lokal, suku Sunda, budaya perbatasan.

PENDAHULUAN UUD 1945 telah menjelaskan bahwa bahasa negara dan bahasa nasionalnya adalah bahasa Indonesia. Namun demikian, Indonesia juga sangat kaya dengan bahasa daerah. Kekayaan itu di satu sisi merupakan kebanggaan, di sisi lain menjadi tugas yang tidak ringan, terutama apabila memikirkan bagaimana cara melindungi, menggali manfaat, dan mempertahankan keberagamannya. Dalam Ethnoloque (2012) disebutkan bahwa terdapat 726 bahasa di Indonesia. Sebagian masih akan berkembang, tetapi tidak dapat diingkari bahwa sebagian besar bahasa itu akan punah. 
Bahasa Sunda adalah salah satu bahasa daerah yang biasa digunakan di beberapa daerah di Indonesia. Bahasa Sunda ini juga merupakan salah satu mata pelajaran yang dipelajari siswa sekolah dasar (SD), yang berdasarkan kurikulum dan kebijakan di beberapa daerah, khususnya di provinsi Jawa Barat. Ironisnya, hasil penelitian para ahli terdahulu, saat ini sekitar 6000 sampai 7000 bahasa etnis atau bahasa daerah di berbagai belahan dunia terancam punah. Begitu pula dengan Bahasa Sunda, yang marak dikabarkan akan terancam punah. Penyebabnya tiada lain adalah keberadaan bahasa Sunda itu sendiri yang sangat jarang digunakan lagi oleh masyarakat Sunda, terlebih lagi masyarakat wilayah perbatasan, semisal Kota Bogor yang secara geografis dan kultural berbatasan dengan Betawi.

Langkah Pemerintah Kota (Pemkot) Bogor yang mewajibkan hari Rabu sebagai hari Nyunda, merupakan upaya positif untuk sedikitnya dapat menjawab permasalahan tergerusnya budaya (termasuk bahasa) Sunda di wilayahnya yang notabene merupakan perbatasan (Astuti, 2014). Meskipun tak dapat dimungkiri, bahwa kekhawatiran Pemkot Bogor yang menetaskan peraturan di atas sangat beralasan, mengingat pentingnya masyarakat Jawa Barat khususnya Kota Bogor, untuk berusaha mempertahankan bahasa daerahnya yaitu bahasa Sunda agar tidak punah. Kekhawatiran ini berdasar pada jarangnya penggunaan bahasa sunda sebagai bahasa keseharian. Bahasa sunda hanya dipakai dalam ruang-ruang kelas formal di sekolah dasar atau sekolah menengah pertama.Namun pada kenyataannya, penulis sebagai guru sekolah dasar di salahsatu SDN di Kota Bogor, menemukan fakta mengejutkan tentang penggunaan bahasa Sunda di sekolah dasar. Bahasa sunda tidak digunakan sebagai bahasa keseharian bagi semua siswa sekolah dasar, bahkan bahasa sunda dianggap sebagai mata pelajaran yang sulit. Untuk itu, kebijakan Pemkot Bogor ini patut diapresiasi, sebagai bentuk contoh peraturan daerah yang memfasilitasi terlestarikannya budaya dan bahasa Sunda yang kian berada di posisi kritis.

Tulisan ini memaparkan hasil penelitian mengenai gambaran intensitas penggunaan bahasa Sunda,baik dalam keseharian siswa maupun dalam pembelajaran di SDN Kayumanis
1 Kota Bogor, respon siswa mengenai pembelajaran bahasa Sunda, faktor apa yang menyebabkan kurangnya minat siswa terhadap pelajaran dan penggunaan bahasa Sunda, serta langkah strategis kebijakan pemerintah pusat dan daerah dalam melindungi bahasa daerah, khususnya bahasa Sunda.

Pada penelitian ini, penulis mengkaji beberapa materi dan teori yang mendasari penelitian ini.

\section{Pengertian Bahasa}

Kata bahasa dalam bahasa Indonesia memiliki lebih dari satu makna atau pengertian. Sapir (1221), Keraf (1984), dan Badudu (1989), memberikan batasan bahwa bahasa itu menonjolkan fungsi, namun ada pakar-pakar yang tidak menonjolkan fungsi, tetapi menonjolkan sosok bahasa itu.Seperti apa yang dikemukakan pula oleh Kridalaksana (1983) dan juga Kentjono(1982), yaitu "Bahasa adalah sistem lambang bunyi yang arbiter yang digunakan oleh para anggota kelompok sosial untuk bekerja sama, berkomunikasi, dan mengidentifikasikan diri".

Istilah bahasa sering digunakan dalam arti kiasan dan dalam arti harfiah. Bahasa yang digunakan dalam arti kiasan seperti "bahasa tari", "bahasa tubuh", "bahasa alam", dan sebagainya. Adapun arti bahasa dalam arti harfiah seperti yang kita temukan dalam ungkapan seperti "ilmu bahasa", "bahasa Indonesia", "Bahasa Inggris", dan lain sebagainya.

Dalam pengertian demikian maka kita akan mengenal istilahlanguage, langue, dan parole. Language yaitu objek yang paling abstrak, karena dia berwujudbahasa secara universal. Langueyaitu objek yang abstrak, karena langue itu berwujud sistem suatu bahasa tertentu secara keseluruhan. Sedangkan parole yaitu objek konkret, karena parole itu berwujud ujaran nyata yang diucapkan.

Sebagai objek kajian, parole merupakan objek konkret karena parole itu berwujud ujaran nyata diucapkan oleh para bahasawan dari suatu masyarakat bahasa. Langue merupakan objek yang abstrak karena langue itu berwujud sistem suatu bahasa tertentu secara keseluruhan, sedangkan language merupakan objek yang paling abstrak karena dia berwujud sistem 
bahasa secara universal. Yang dikaji linguistik secara langsung adalah parole itu, karena parole itulah yang berwujud konkret, yang nyata, yang dapat diamati, atau diobservasi. Kajian terhadap parole dilakukan untuk mendapatkan kadiahkaidah suatu langue, dan dari kajian terhadap langue ini akan diperoleh kaidah-kaidah language, kaidah bahasa secara universal.

Meskipun bahasa itu tidak pernah lepas dari manusia, dalam arti, tidak ada kegiatan manusia yang tidak disertai bahasa, tetapi karena rumitnya menentukan suatu parole bahasa atau bukan, hanya dialeg saja dari bahasa yang lain, maka hingga kini belum pernah ada berapa angka yang pasti, berapa jumlah bahasa yang ada di dunia ini.

\section{Bahasa Daerah dan Peraturan Perundang- undangan}

Pengaturan tentang bahasa daerah dalam peraturan perundang-undangan bukanlah hal utama, kecuali dalam beberapa perda. Pengaturan penggunaan bahasa daerah menjadi pelengkap pengaturan tentang bahasa Indonesia atau bahasa negara. Dalam Undang-Undang Nomor 20 Tahun 2003 tentang Sistem Pendidikan Nasional-termasuk UndangUndang Nomor 4 Tahun 1950 Undang-Undang Nomor 12 Tahun 1954 dan Undang-Undang Nomor 2 Tahun 1989 yang menjadi cikal bakal Undang-Undang Nomor 20 Tahun 2003penggunaan bahasa daerah diatur sebagai pelengkap penggunaan bahasa Indonesia yang diwajibkan dalam penyelenggaraan pendidikan nasional di Indonesia. Bahasa daerah boleh digunakan pada tahap awal pendidikan untuk menyampaikan pengetahuan dan keterampilan tertentu. Senada dengan itu, bahasa asing dapat pula digunakan sebagai bahasa pengantar untuk mendukung pemerolehan kemahiran berbahasa asing peserta didik. Baik bahasa daerah maupun bahasa asing mempunyi fungsi pendukung bahasa Indonesia sebagai bahasa pengantar utama dalam sistem pendidikan nasional.

Berkaitan dengan upaya pengembangan, pembinaan, dan pelindungan bahasa, UndangUndang Nomor 24 Tahun 2009 memberikan kewenangan dan kewajiban penanganan bahasa dan sastra Indonesia kepada pemerintah pusat dan memberikan kewenangan dan kewajiban penangan bahasa dan sastra daerah kepada pemerintah daerah. Akan tetapi, dalam hal itu semua pemerintah pusat diberi juga kewenangan merumuskan kebijakan nasional kebahasaan yang di dalamnya juga memuat kebijakan tentang apa dan bagaimana pengembangan, pembinaan, dan pelindungan bahasa daerah itu harus dilakukan. Pemerintah daerah juga diberi kewajiban mendukung pengembangan, pembinaan, dan pelindungan bahasa Indonesia. Sebaliknya, pemerintah pusat juga harus memberikan dukungan, baik dukungan pendanaan maupun kepakaran, kepada pemerintah daerah dalam menyelenggarakan pengembangan, pembinaan, dan pelindungan bahasa daerah.

Berdasarkan Pasal 41 dan Pasal 42 UndangUndang Nomor 24 Tahun 2009, penanganan bahasa dan sastra daerah menjadi tanggung jawab pemerintah daerah dan dalam pelaksanaan tanggung jawab itu, pemerintah daerah harus berkoordinasi dengan pemerintah pusat sebagai pembuat kebijakan nasional kebahasaan. Selain berupa pembagian tugas yang lebih terperinci, koordinasi itu dapat juga berupa fasilitasi kepakaran dan dukungan sumber daya.

Penanganan terhadap bahasa dan sastra daerah diklasifikasikan ke dalam tiga hal, yaitu pengembangan, pembinaan, dan pelindungan bahasa dan sastra daerah. Dalam pengembangan bahasa dilakukan upaya memodernkan bahasa melalui pemerkayaan kosakata, pemantapan dan pembakuan sistem bahasa, dan pengembangan laras bahasa. Dalam pembinaan bahasa dilakukan upaya meningkatkan mutu penggunaan bahasa melalui pembelajaran bahasa serta pemasyarakatan bahasa ke berbagai lapisan masyarakat. Selain itu, pembinaan bahasa juga dimaksudkan untuk meningkatkan kedisiplinan, keteladanan, dan sikap positif masyarakat terhadap bahasa itu. Sementara itu, upaya pelindungan dilakukan dengan menjaga dan memelihara kelestarian bahasa melalui penelitian, pengembangan, pembinaan, dan pengajarannya.

Berdasarkan kriteria yang ditetapkan UNESCO, vitalitas bahasa digolongkan menjadi enam kelompok (Salminen, 1999), yaitu

1. Bahasa yang punah (extinct languages), bahasa tanpa penutur lagi; 
2. Bahasa hampir punah (nearly extinct languages), bahasa dengan sebanyakbanyaknya sepuluh penutur yang semuanya generasi tua;

3. Bahasa yang sangat terancam (seriously endangered languages), bahasa dengan jumlah penutur yang masih banyak, tetapi anak-anak mereka sudah tidak menggunakan bahasa itu;

4. Bahasa terancam (endangered languages), bahasa dengan penutur anak-anak, tetapi cenderung menurun;

5. Bahasa yang potensial terancam (potentiallyendangered languages) bahasa dengan banyak penutur anak-anak, tetapi bahasa itu tidak memiliki status resmi atau yang prestisius;

6. Bahasa yang tidak terancam (not endangered languages), bahasa yang memiliki transmisi ke generasi baru yang sangat bagus.

Bahasa di Indonesia mempunyai jumlah penutur yang sangat beragam. Vitalitas bahasa daerah di Indonesia menyebar dari status yang paling aman hingga yang benar-benar punah. Di antara bahasa di Indonesia, terdapat tiga bahasa yang penuturnya lebih dari 10 juta jiwa, yaitu bahasa Jawa (penuturnya 84,3 juta jiwa), bahasa Sunda (penuturnya 34 juta jiwa), dan bahasa Madura (penuturnya 13,6 juta jiwa).

Penanganan bahasa daerah diklasifikasikan berdasarkan pengelompokkan vitalitas bahasa tersebut. Pengembangan dan pembinaan dilakukan terhadap bahasa masih dalam status tidak terancam (aman), yaitu bahasa yang digunakan oleh penutur dari generasi muda sampai dengan generasi tua hampir terdapat dalam semua ranah, dan terhadap bahasa yang mempunyai potensi terancam, yaitu bahasa yang penutur anak-anaknya masih banyak, tetapi bahasa itu tidak memiliki status resmi atau status yang prestisius. Bahasa dalam vitalitas kedua itu masih dapat direvitalisasi. Dengan pengembangan bahasa itu, kita akan mempunyai korpus yang memadai untuk membahasakan apa saja, mempunyai akselerasi yang bagus terhadap dunia pendidikan dan perkembangan iptek, serta dapat mengantisipasi munculnya media baru. Pembinaan dilakukan agar bahasa itu mempunyai transmisi antargenerasi yang baik, baik transmisi melalui dunia pendidikan maupun transmisi melalu interaksi dalam ranah keluarga. Termasuk dalam upaya pengembangan dan pelindungan adalah memantapkan status bahasa, mengoptimalkan dokumentasi, serta menumbuhkan sikap positif penuturnya.

Pelindungan terhadap bahasa dilakukan sekurang-kurangnya dua tingkat, yaitu tingkat dokumentasi dan tingkat revitalisasi. Pelindungan bahasa di tingkat dokumentasi akan dilakukan pada bahasa yang sudah tidak ada harapan untuk digunakan kembali oleh masyarakatnya. Bahasa yang dalam keadaan hampir punah dan bahasa yang sangat teracam hanya dapat dilindungi dengan mendukokumentasikan bahasa itu sebelum bahasa itu punah yang sebenarnya. Dokumentasi itu penting untuk menyiapkan bahan kajian jika suatu saat diperlukan.

Pelindungan terhadap bahasa yang masih digunakan oleh penutur dari sebagian generasi muda dalam hampir semua ranah atau oleh semua generasi muda dalam ranah keluarga dan agama serta kegiatan adat dilakukan revitalisasi untuk pelestarian. Untuk revitalisasi itu, diperlukan tahap pendahuluan yang meliputi pedokumentasian, pengkajian, dan penyusunan bahan revitalisasi, seperti kamus, tata bahasa, dan bahan ajar. Untuk bahasa yang akan direvitalisasi, harus disiapkan sistem ortografi yang memungkinkan bahasa itu diterima dalam media baru.

\section{METODE}

Penelitian dilakukan selama tiga bulan di SDN Kayumanis 1 yang beralamat di jalan Pool Binamarga No. 1 Kelurahan Kayumanis Kecamatan Tanah Sareal Kota Bogor, dengan pertimbangan sebagai berikut.

1. Peneliti bertugas di sekolah tersebut, sehingga peneliti merasa memiliki tanggung jawab atas permasalahan tersebut.

2. Peneliti memperoleh kemudahan dalam memperoleh izin penelitian dan pengambilan data.

Subjek penelitian dalam penelitian ini yaitu siswa kelas I, siswa kelas II, siswa kelas III, siswa kelas IV, dan siswa kelas V SDN Kayumanis 1. Pemilihan subjek penelitian tersebut atas pertimbangan penemuan masalah yang ada di subjek penelitian.

Metode yang digunakan dalam penelitian ini adalah metode penelitian deskriptif. Metode 
penelitian deskriptif adalah suatu metode penelitian yang ditujukan untuk menggambarkan fenomena-fenomena yang ada yang berlangsung pada saat ini atau saat yang lampau, (Sukmadinata, 2011). Withney (1960) berpendapat, metode deskriptif adalah pencarian fakta dengan interpretasi yang tepat. Penelitian deskriptif juga berarti penelitian yang dimaksudkan untuk menjelaskan fenomena atau karakteristik individual, situasi atau kelompok tertentu secara akurat. Penelitian deskriptif merupakan cara untuk menemukan makna baru, menjelaskan sebuah kondisi keberadaan, menentukan frekuensi kemunculan sesuatu dan mengkategorikan informasi.

Berkaitan dengan instrumen yang digunakan dalam penelitian ini, kegiatan pengisian angket dan observasi lapanganmerupakan elemen utama yang dijadikan alat pengumpul data penelitian. Dalam pengolahan angket, digunakan skala persentase berdasarkan pendapat Kuntjaraningrat (Maulana, 2006) sebagai berikut ini:

Tabel 1. Krtiteria Persentase Angket

\begin{tabular}{|c|c|}
\hline Persentase & Kriteria \\
\hline $\mathrm{p}=0 \%$ & Tak ada seorang pun \\
\hline $0 \%<\mathrm{p}<25$ & Sebagian kecil \\
\hline $25 \leq \mathrm{p}<50$ & Hampir setengahnya \\
\hline $\mathrm{p}=50 \%$ & Setengahnya \\
\hline $50<\mathrm{p}<75$ & Sebagian besar \\
\hline $75 \leq \mathrm{p}<100$ & Hampir seluruhnya \\
\hline $\mathrm{p}=100$ & Seluruhnya \\
\hline
\end{tabular}

\section{HASIL DAN PEMBAHASAN}

Angket yang didistribusikan kepada subjek penelitian ini berfokus pada sepuluh poin penting, yakni: (1) bahasa sehari-hari yang digunakan di rumah, (2) bahasa yang biasa digunakan ibu (orangtua) di rumah, (3) bahasa yang biasa digunakan ayah (orangtua) di rumah, (4) bahasa yang biasa digunakan siswa dalam lingkungan pergaulan di sekolah, (5) bahasa yang digunakan guru di sekolah, (6) bahasa yang sering dipakai rekan-rekan siswa di sekolah, (7) apakah siswa menyukai pelajaran Bahasa Sunda atau tidak (8) pendapat siswa tentang pelajaran Bahasa Sunda, (9) kebiasaan belajar siswa sebelum pelajaran Bahasa Sunda dimulai,dan (10) pendapat siswa mengenai proses pembelajaran Bahasa Sunda di sekolah. Dalam pengolahan datanya, untuk lebih memudahkan pembaca, maka kelompok responden dibagi menjadi dua bagian, yakni kelompok responden siswa kelas rendah (kelas I, II, dan III) serta kelas tinggi (kelas IV dan V).

Secara ringkas, diperoleh rekapitulasi data dari kedua kelompok responden tadi sebagai berikut ini.

Tabel 1. Respon Siswa Kelas Rendah terhadap Penggunaan dan Pembelajaran Bahasa Sunda

\begin{tabular}{|c|c|c|c|c|c|c|c|c|c|c|}
\hline It & \multicolumn{10}{|c|}{ Persentase (\%) Jawaban terhadap Item ke- } \\
\hline m & 1 & 2 & 3 & 4 & 5 & 6 & 7 & 8 & 9 & 10 \\
\hline $\mathbf{A}$ & $\begin{array}{c}4 . \\
08\end{array}$ & $\begin{array}{r}6 \\
12\end{array}$ & $\begin{array}{l}.2 \\
2\end{array}$ & $\begin{array}{c}3 . \\
06\end{array}$ & $\begin{array}{r}5 . \\
10\end{array}$ & $\begin{array}{r}4 . \\
08\end{array}$ & $\begin{array}{r}38 \\
.7 \\
8\end{array}$ & $\begin{array}{r}35 \\
.7 \\
1\end{array}$ & $\begin{array}{r}75 \\
.5 \\
1\end{array}$ & $\begin{array}{r}58 \\
.1 \\
6\end{array}$ \\
\hline B & $\begin{array}{c}3 . \\
06\end{array}$ & $\begin{array}{c}8 . \\
16\end{array}$ & $\begin{array}{r}11 \\
.2 \\
2 \\
\end{array}$ & $\begin{array}{c}3 . \\
06\end{array}$ & $\begin{array}{r}9 . \\
18\end{array}$ & $\begin{array}{r}2 . \\
04\end{array}$ & $\begin{array}{r}11 \\
.2 \\
2\end{array}$ & $\begin{array}{r}21 \\
.4 \\
3\end{array}$ & $\begin{array}{r}16 \\
.3 \\
3 \\
\end{array}$ & $\begin{array}{r}18 \\
.3 \\
7 \\
\end{array}$ \\
\hline C & $\begin{array}{r}90 \\
.8 \\
2\end{array}$ & $\begin{array}{r}79 \\
.5 \\
9\end{array}$ & $\begin{array}{r}73 \\
.4 \\
7\end{array}$ & $\begin{array}{r}90 \\
.8 \\
2\end{array}$ & $\begin{array}{r}83 \\
.6 \\
7\end{array}$ & $\begin{array}{r}89 \\
.8 \\
0\end{array}$ & $\begin{array}{r}30 \\
.6 \\
1\end{array}$ & $\begin{array}{r}24 \\
.4 \\
9\end{array}$ & $\begin{array}{l}3 . \\
06\end{array}$ & $\begin{array}{r}18 \\
.3 \\
7\end{array}$ \\
\hline D & $\begin{array}{c}2 . \\
04\end{array}$ & $\begin{array}{r}6 . \\
12\end{array}$ & $\begin{array}{r}4 . \\
08\end{array}$ & $\begin{array}{c}2 . \\
04\end{array}$ & $\begin{array}{r}2 . \\
04\end{array}$ & $\begin{array}{r}4 . \\
08\end{array}$ & $\begin{array}{r}14 \\
.2 \\
9\end{array}$ & $\begin{array}{r}14 \\
.2 \\
9\end{array}$ & $\begin{array}{r}1 . \\
02\end{array}$ & $\begin{array}{c}1 . \\
02\end{array}$ \\
\hline
\end{tabular}

Dari siswa kelas rendah yang berjumlah 98 orang siswa (terdiri dari 31 orang kelas I, 35 orang kelas II, dan 32 orang kelas III). Diperoleh informasi sebagai berikut ini. Berdasarkan data yang terkumpul, diketahui bahwa bahasa yang digunakan siswa di rumah, sebagian kecil saja yang menggunakan bahasa Jawa $(4,08 \%)$, bahasa Sunda $(3,06 \%)$ atau bahasa lainnya $(2,04 \%)$, sementara hampir seluruhnya (90,82\%) menggunakan bahasa Indonesia.

Orangtua siswa, antara ibu dan ayah, ternyata terdapat perbedaan penggunaan bahasa, ini terlihat dari $8,16 \%$ ibu dan $11,22 \%$ ayah menggunakan bahasa Sunda, 6,12\% ibu dan $11,22 \%$ ayah menggunakan bahasa Jawa, sementara hampir seluruh ibu $(79,59 \%)$ dan sebagian besar ayah $(73,47 \%)$ yang menggunakan bahasa Indonesia sebagai bahasa keseharian di rumah.

Penggunaan bahasa oleh siswa yang dominan di sekolah adalah bahasa Indonesia (90,82\%), hanya sebagian kecil siswa menggunakan bahasa Sunda, Jawa (masing-masing 3,06\%) maupun bahasa lainnya $(2,04 \%)$, dan ada $1 \%$ responden yang tidak memberikan jawaban. Adapun jika ditinjau dari guru sebagai pengguna bahasanya, 
maka komunikasi guru yang menggunakan bahasa Sunda diakui oleh 9,18\% siswa, sedangkan komunikasi dalam bahasa Indonesia diakui oleh hampir seluruh siswa $(83,67 \%)$, dan sisanya menggunakan bahasa Jawa atau bahasa lainnya. Lalu dengan melihat lingkungan pergaulan sehari-hari di sekolah, menurut responden, teman-temannya hampir seluruhnya menggunakan bahasa Indonesia (89,80\%), lalu ada $4,08 \%$ pengguna bahasa Jawa, dan jauh leih kecil lagi persentase pengguna bahasa Sunda, yakni hanya 2,04\%.

Berikutnya item pertanyaan yang diajukan lebih berfokus kepada kecenderungan sikap dan perasaan mereka terhadap penggunaan bahasa Sunda baik sebagai bahasa kolokial maupun sebagai matapelajaran. Sebagian besar siswa (69,39\%) menyatakan bahwa sikap positif terhadap pelajaran Bahasa Sunda, yang terdiri dari mereka yang menunjukkan perasaan suka sebanyak 38,78\% dan menyatakan sangat suka sebesar 30,61\%. Kemudian ada 11,22\% siswa yang menyatakan tidak suka serta $14,29 \%$ sangat tidak suka pelajaran Bahasa Sunda, sehingga total siswa kelas rendah yang cenderung berespon negatif adalah sebanyak 25,51\%. Di samping itu, 5\% siswa tidak memberikan pernyataan.

Pendapat siswa mengenai pembelajaran Bahasa Sunda yang selama ini dipelajari oleh mereka, hampir setengahnya (35,71\%) menyatakan bahwa pelajaran Bahasa Sunda sangat menyenangkan karena memang mengerti bahasa Sunda. Sebagian kecil siswa (21,43\%) menyatakan bahwa pelajaran Bahasa Sunda menyenangkan, karena walaupun siswa tidak mengerti, tetapi mereka bisa bertanya kepada ke orang tua. Sebagian kecil siswa (24,49\%) menyatakan bahwa mereka sulit mempelajarinya karena saya tidak mengerti bahasa Sunda, dan $14,29 \%$ siswa menyatakan bahwa pelajaran Bahasa Sunda itu sangat sulit dan membosankan, dengan alasanbahwa mereka tidak tahu samasekali tentang bahasa Sunda.

Item kesembilan dari angket yang didistribusikan, mempertanyakan kepada responden mengenai apa yang biasanyadilakukan sebelum pelajaran Bahasa Sunda dimulai. Lalu terkumpullah data, di mana hampir seluruhnya $(75,51 \%)$ belajar dahulu di rumah, mempelajari bab yang akan diajarkan guru dan mengerjakan tugas yang diberikan guru sebelumnya. Kemudian ada sebagian kecil $(16,33 \%)$ yang menyatakan hanya mengerjakan sendiri tugas di rumah, dan jika tidak ada tugas maka mereka pun tidak belajar. Sebanyak 3,06\% siswa lebih bersantai-santai di rumah karena yang mengerjakan tugas Bahasa Sunda adalah orang tuanya (atau, pekerjaan rumah tersebut dibantu orang tua). Banyaknya siswa yang menyatakan bersantai-santai di rumah, karena ketika ada tugas Bahasa Sunda, mereka aka mencontek pada temannya di sekolah adalah hanya $1,02 \%$.

Terakhir, secara umum pendapat siswa sekolah dasar kelas rendah mengenai proses pembelajaran Bahasa Sunda di sekolahnya, sebanyak 58,16\% (sebagian besar) menyatakan pembelajarannya menyenangkan, sebagian kecil $(18,37 \%)$ menyatakan pembelajarannya membosankan, sebagian kecil (18,37\%) menyatakan biasa saja, dan hanya $1,02 \%$ saja yang menyatakan bahwa pembelajaran Bahasa Sunda itu menyebalkan.

Bahasan berikutnya adalah tentang aspek kebiasaan dan sikap siswa kelas tinggi terhadap penggunaan dan pembelajaran Bahasa Sunda. Jumlah responden adalah 80 orang, terdiri dari 39 siswa kelas IV 41 siswa kelas V. Berikut ini rekapitulasi hasil secara umum.

Tabel 2. Respon Siswa Kelas Tinggi terhadap Penggunaan dan Pembelajaran Bahasa Sunda

\begin{tabular}{|c|c|c|c|c|c|c|c|c|c|c|}
\hline \multirow{2}{*}{$\begin{array}{c}\text { It } \\
\text { e } \\
\text { m }\end{array}$} & \multicolumn{10}{|c|}{ Persentase (\%) Jawaban terhadap Item ke- } \\
\hline & 1 & 2 & 3 & 4 & 5 & 6 & 7 & 8 & 9 & 10 \\
\hline $\mathbf{A}$ & 0 & $\begin{array}{r}1 . \\
25\end{array}$ & $\begin{array}{r}2 . \\
50\end{array}$ & 0 & 0 & 0 & $\begin{array}{r}27 \\
.5 \\
0\end{array}$ & $\begin{array}{r}10 \\
.0 \\
0\end{array}$ & $\begin{array}{r}75 \\
.0 \\
0\end{array}$ & $\begin{array}{r}20 \\
.0 \\
0\end{array}$ \\
\hline B & $\begin{array}{r}1 . \\
25\end{array}$ & $\begin{array}{c}5 . \\
00\end{array}$ & $\begin{array}{r}3 . \\
75\end{array}$ & 0 & $\begin{array}{r}3 . \\
75\end{array}$ & 0 & $\begin{array}{r}51 \\
.2 \\
5 \\
\end{array}$ & $\begin{array}{r}41 \\
.2 \\
5 \\
\end{array}$ & $\begin{array}{r}17 \\
.5 \\
0 \\
\end{array}$ & $\begin{array}{r}10 \\
.0 \\
0 \\
\end{array}$ \\
\hline C & $\begin{array}{r}97 \\
.5 \\
0\end{array}$ & $\begin{array}{r}92 \\
.5 \\
0\end{array}$ & $\begin{array}{r}92 \\
.5 \\
0\end{array}$ & $\begin{array}{l}0 \\
0\end{array}$ & $\begin{array}{r}95 \\
.0 \\
0\end{array}$ & $\begin{array}{r}98 \\
.7 \\
5\end{array}$ & $\begin{array}{r}11 \\
.2 \\
5\end{array}$ & $\begin{array}{r}38 \\
.7 \\
5\end{array}$ & $\begin{array}{r}6 . \\
25\end{array}$ & $\begin{array}{r}61 \\
.2 \\
5\end{array}$ \\
\hline $\mathbf{D}$ & $\begin{array}{r}1 . \\
25\end{array}$ & $\begin{array}{r}1 . \\
25\end{array}$ & $\begin{array}{r}1 . \\
25\end{array}$ & 0 & $\begin{array}{c}1 . \\
25\end{array}$ & $\begin{array}{l}1 . \\
25\end{array}$ & $\begin{array}{c}8 . \\
75\end{array}$ & $\begin{array}{r}10 \\
.0 \\
0\end{array}$ & $\begin{array}{r}1 . \\
25\end{array}$ & $\begin{array}{r}8 . \\
75\end{array}$ \\
\hline
\end{tabular}

Dari jumlah siswa kelas tinggi sebanyak 80 orang, diperoleh informasi sebagai berikut ini. Berdasarkan data yang terkumpul, diketahui bahwa bahasa yang digunakan siswa di rumah, sebagian kecil saja (1,25\%) yang menggunakan 
bahasa Sunda atau bahasa lainnya, dan tak ada satupun siswa kelas tinggi yang menggunakan bahasa Jawa di rumahnya. Sementara itu, hampir seluruhnya $(97,50 \%)$ menggunakan bahasa Indonesia. Begitu pula dengan orangtua siswa, terdapat $5,00 \%$ ibu dan $3,75 \%$ ayah menggunakan bahasa Sunda, 1,25\% ibu dan $2,50 \%$ ayah menggunakan bahasa Jawa, sementara hampir seluruh ibu dan ayah dengan persentase sama sebesar 92,50\% menggunakan bahasa Indonesia sebagai bahasa kolokialnya.

Di wilayah perbatasan budaya seperti Kecamatan Tanah Sareal Kota Bogor, ternyata seluruh siswa (100\%) menggunakan bahasa Indonesia di sekolah. Sementara itu, berdasarkan pengakuan siswa, setidaknya ada sebagian kecil guru $(3,75 \%)$ yang biasa menggunakan bahasa Sunda di sekolah dan 1,25\% menggunakan bahasa lain selain bahasa Jawa. Kedudukan bahasa Indonesia benar-benar sangat dominan di sekolah, mengingat 95,00\% guru menggunakannya dalam komunikasinya bersama siswa. Adapun jika ditinjau dari lingkungan pergaulan sehari-hari di sekolah, menurut responden, teman-temannya hampir seluruhnya menggunakan bahasa Indonesia $(98,75 \%)$, dan tidak ada satupun yang menggunakan baik bahasa Sunda maupun Jawa.

Item pertanyaan ketujuh sampai dengan kesepuluh, diajukan untuk lebih menggali kecenderungan sikap dan perasaan siswa kelas tinggi terhadap penggunaan bahasa Sunda baik sebagai bahasa kolokial maupun sebagai suatu matapelajaran. Sebagian besar dari jumlah siswa (78,75\%) menampakkan kecenderungan sikap siswa yang positif terhadap pelajaran Bahasa Sunda, yang terdiri dari mereka yang menunjukkan perasaan suka sebanyak 27,50\% dan menyatakan sangat suka sebesar 51,25\%. Kemudian ada 11,25\% siswa yang menyatakan tidak suka serta $8,75 \%$ sangat tidak suka pelajaran Bahasa Sunda, sehingga total siswa kelas tinggi yang cenderung berespon negatif adalah sebanyak 20,00\% (sebagian kecil saja).

Berdasarkan hasil yang diperoleh, sebagian kecil (10,00\%) menyatakan bahwa pelajaran Bahasa Sunda sangat menyenangkan karena memang mengerti bahasa Sunda, dan hampir setengahnya (41,25\%) menyatakan bahwa pelajaran Bahasa Sunda menyenangkan, karena walaupun siswa tidak mengerti, tetapi mereka bisa bertanya kepada ke orang tua. Hampir setengah dari jumlah siswa siswa $(38,75)$ menyatakan bahwa mereka sulit mempelajarinya karena saya tidak mengerti bahasa Sunda, dan ada pula siswa yang menyatakan bahwa pelajaran Bahasa Sunda itu sangat sulit dan membosankan, dengan alasanbahwa mereka tidak tahu samasekali tentang bahasa Sunda. Untuk pernyataan terakhir ini, persentase sebesar $10,00 \%$.

Berikutnya, responden yang menyatakan bahwa mereka belajar dahulu di rumah, mempelajari bab yang akan diajarkan guru dan mengerjakan tugas yang diberikan guru sebelumnya, adalah sebanyak 75,00\% (hampir seluruhnya). Kemudian ada sebagian kecil $(17,50 \%)$ yang menyatakan hanya mengerjakan sendiri tugas di rumah, dan jika tidak ada tugas maka mereka pun tidak belajar. Sebanyak 6,25\% siswa lebih bersantai-santai di rumah karena yang mengerjakan tugas Bahasa Sunda adalah orang tuanya (atau, pekerjaan rumah tersebut dibantu orang tua). Namun untuk kelas tinggi ini pun masih saja ada siswa (1,02\%) yang menyatakan bersantai-santai di rumah, karena ketika ada tugas Bahasa Sunda, mereka aka mencontek pada temannya di sekolah.

Pada bagian terakhir, secara umum pendapat siswa SD kelas tinggi mengenai proses pembelajaran Bahasa Sunda di sekolahnya, sebagian kecil (20,00\%) menyatakan pembelajarannya menyenangkan, sebagian kecil lagi $(10,00 \%)$ menyatakan pembelajarannya membosankan, sebagian besar siswa (61,25\%) menyatakan bahwa pembelajaran Bahasa Sunda biasa-biasa saja, dan hanya sebagian kecil sisanya $(8,75 \%)$ menyatakan bahwa pembelajaran Bahasa Sunda itu menyebalkan.

\section{SIMPULAN}

Berdasarkan hasil penelitian dan pembahasan tersebut, penulis menyimpulkan bahwa:

1. Intensitas penggunaan bahasa Sunda dalam keseharian siswa sangat kurang.

2. Siswa memandang pelajaran Bahasa Sunda merupakan pelajaran yang sulit.

3. Faktor penyebab kurangnya minat siswa baik dalam pembelajaran Bahasa Sunda maupun penggunaan bahasa Sunda yaitu karena ketidakmengertian siswa dalam pengertian kata-kata Sunda. 
4. Pemerintah Kota Bogor sudah berusaha melakukan upaya pelestarian bahasa Sunda, namun masih belum optimal dan merata.

Berdasarkan hasil penelitian dan pembahasan di atas, dapat dikemukakan saran agar seluruh siswa, masyarakat dan pemerintah terus melestarikan bahasa Sunda dengan mempelajari dan menggunakannya dengan baik dan benar sehingga terhindar dari kepunahan bahasa daerah.

\section{REFERENSI}

Astuti, K.D. (2014). Rebo Nyunda Mulai Diterapkan di Bogor. Pikiran Rakyat. 5 November, hal. 16.

Badudu, Jusuf Sjarif. (1989).Hakikat Bahasa. Tersedia: http://meystkip. wordpress.com/materi-kuliah/hakikat-bahasa/ [22 September 2014]

Ethnoloque. (2012). Perlindungan Bahasa Daerah dalam Kerangka Kebijakan Nasional Kebahasaan. Tersedia: http://badanbahasa.kemdikbud.go.id/ lamanbahasa/artikel/1343[22 September 2014]

Kentjono, Dj. (1982). Hakikat Bahasa. Tersedia: http://meystkip. wordpress.com/ materikuliah/hakikat-bahasa/ [22 September 2014]

Keraf, G. (1984). Hakikat Bahasa. Tersedia: http://meystkip.wordpress.com/ materikuliah/hakikat-bahasa/ [22 September 2014]

Kridalaksana(1983). Hakikat Bahasa. Tersedia:http://meystkip.wordpress.com/ materi-kuliah/hakikat-bahasa/
Maulana (2006). Alternatif Perkuliahan Matematika dengan Menggunakan Metafora. Jurnal Pendidikan Dasar, No.1 Bulan April.

Salminen (1999). Bahasa Daerah dan Peraturan Perundang-undangan. Tersedia: http://badanbahasa.kemdikbud.go.id/lamanb ahasa/artikel/1343[22 September 2014]

Sapir, E. (1221). Hakikat Bahasa. Tersedia: http://meystkip.wordpress.com/ materikuliah/hakikat-bahasa/[22 September 2014]

Sukmadinata, N.S. (2011). Metode Penelitian Deskriptif. Tersedia: http:// daun2001.blogspot.com/2013/05/rancanganpenelitian-deskriptif.html[22 September 2014]

Withney (1960). Metode Penelitian Deskriptif. Tersedia: http://daun2001. blogspot.com/2013/05/rancangan-penelitiandeskriptif.html[22 September 2014].

Undang-Undang Nomor 20 Tahun 2003 tentang Sistem Pendidikan Nasional.

Undang-Undang Nomor 4 Tahun 1950 tentang Dasar-dasar Pendidikan dan Pengajaran.

Undang-Undang Nomor 12 Tahun 1954 tentang Dasar-Dasar Pendidikan dan Pengajaran di Sekolah untuk Seluruh Indonesia.

Undang-Undang Nomor 2 Tahun 1989 tentang Sistem Pendidikan Nasional.

Undang-Undang Nomor 24 Tahun 2009 tentang Bendera, Bahasa, dan Lambang Negara, serta Lagu Kebangsaan. 